\title{
Neoplasms derived from plasmacytoid dendritic cells
}

\author{
Fabio Facchetti ${ }^{1}$, Marta Cigognetti ${ }^{1}$, Simona Fisogni ${ }^{1}$, Giuseppe Rossi ${ }^{2}$, Silvia Lonardi ${ }^{1}$ and \\ William Vermi ${ }^{1}$ \\ ${ }^{1}$ Section of Pathology, Department of Molecular and Translational Medicine, Spedali Civili, University of \\ Brescia, Brescia, Italy and ${ }^{2}$ Department of Hematology, Spedali Civili, Brescia, Italy
}

\begin{abstract}
Plasmacytoid dendritic cell neoplasms manifest in two clinically and pathologically distinct forms. The first variant is represented by nodular aggregates of clonally expanded plasmacytoid dendritic cells found in lymph nodes, skin, and bone marrow ('Mature plasmacytoid dendritic cells proliferation associated with myeloid neoplasms'). This entity is rare, although likely underestimated in incidence, and affects predominantly males. Almost invariably, it is associated with a myeloid neoplasm such as chronic myelomonocytic leukemia or other myeloid proliferations with monocytic differentiation. The concurrent myeloid neoplasm dominates the clinical pictures and guides treatment. The prognosis is usually dismal, but reflects the evolution of the associated myeloid leukemia rather than progressive expansion of plasmacytoid dendritic cells. A second form of plasmacytoid dendritic cells tumor has been recently reported and described as 'blastic plasmacytoid dendritic cell neoplasm'. In this tumor, which is characterized by a distinctive cutaneous and bone marrow tropism, proliferating cells derive from immediate $\mathrm{CD4}{ }^{+} \mathrm{CD} 56^{+}$precursors of plasmacytoid dendritic cells. The diagnosis of this form can be easily accomplished by immunohistochemistry, using a panel of plasmacytoid dendritic cells markers. The clinical course of blastic plasmacytoid dendritic cell neoplasm is characterized by a rapid progression to systemic disease via hematogenous dissemination. The genomic landscape of this entity is currently under intense investigation. Recurrent somatic mutations have been uncovered in different genes, a finding that may open important perspectives for precision medicine also for this rare, but highly aggressive leukemia.
\end{abstract}

Modern Pathology (2016) 29, 98-111; doi:10.1038/modpathol.2015.145; published online 8 January 2016

Over 50 years ago, Lennert identified a novel nodal cell type, ${ }^{1}$ subsequently defined as plasmacytoid dendritic cells. Studies by pathologists and immunologists (based on morphology, phenotype, and function) recognized the uniqueness of plasmacytoid dendritic cells among other cell types of the innate immune system. Specifically, plasmacytoid dendritic cells are highly specialized circulating cells which are characterized by the ability to produce high levels of type I interferon $(\text { IFN-I })^{2}$ and to differentiate into antigen-presenting dendritic cells in response to a variety of stimuli. ${ }^{3}$ Circulating plasmacytoid dendritic cells home to diseased tissue, particularly skin and lymphoid organs, in various types of inflammatory conditions (autoimmunity, cancer, virus infection), suggesting a

Correspondence: Professor F Facchetti, MD, PhD, Section of Pathology, Department of Molecular and Translational Medicine, Spedali Civili, University of Brescia, Brescia, Brescia 25123, Italy. E-mail: fabio.facchetti@unibs.it

Received 3 August 2015; accepted 10 November 2015; published online 8 January 2016 role in the organization of the adaptive immune response. ${ }^{4-6}$ It has also been shown that plasmacytoid dendritic cells may exert effector functions by releasing cytotoxic molecules, such as tumor necrosis factor-related apoptosis-inducing ligand (TRAIL) and granzyme B. On the basis of the recognition of the murine counterpart of plasmacytoid dendritic cells, ${ }^{7-9}$ it is now possible to better understand the role of these cells in various diseases.

Since the early 1980s, pathologists became aware of the fact that plasmacytoid dendritic cells (or their precursors) could transform and eventually expand clonally. In particular, plasmacytoid dendritic cell neoplasms manifest in two clinically and pathologically distinct forms. The first reported variant ('Mature plasmacytoid dendritic cells proliferation associated with myeloid neoplasms') is invariably associated with a myeloid neoplasm, ${ }^{10}$ whereas the second variant, reported as 'blastic plasmacytoid dendritic cell neoplasm' likely stems from immediate $\mathrm{CD}^{+}{ }^{+} \mathrm{CD} 56^{+}$precursors of plasmacytoid dendritic cells. ${ }^{11}$ On the basis of histology, blastic plasmacytoid dendritic cell neoplasm is now recognizable 
from other leukemia; however, no major advances have been made in terms of prognosis and treatment standardization.

In this review, we will briefly provide a historical background on the identification and characterization of human plasmacytoid dendritic cells, and discuss recent advances on their functional properties. A more detailed analysis of the role of plasmacytoid dendritic cells in various human diseases is provided in several reviews. ${ }^{5,6,12}$ Here we provide a comprehensive overview of the two forms of plasmacytoid dendritic cell neoplasm, with a detailed analysis of clinical and histological finding. The molecular basis of plasmacytoid dendritic cells transformation and progression has remained unknown until recently. For the blastic plasmacytoid dendritic cell neoplasm entity, we have included and commented recent reports on its genomic landscape, with the aim of identifying the Achilles' heel of this highly aggressive neoplasm.

\section{Initial identification and characterization of plasmacytoid dendritic cells}

Plasmacytoid dendritic cells made their first appearance over 50 years ago under the microscope of Karl Lennert as nodal 'lymphoblasts'. ${ }^{1}$ Subsequent morphological and ultrastructural studies led to a series of plausible, although conflicting, designations such as 'T-associated plasma cell', 'plasmacytoid T cell', and 'plasmacytoid T-zone cell'. ${ }^{13}$ The demonstration of the expression of myelomonocytic markers such as CD15 (after neuraminidase treatment) and CD68, and lack of other T-lineage markers, prompted the term 'plasmacytoid monocyte', thus questioning their lymphoid affiliation. ${ }^{14}$ In the late 1990s, it became possible to purify plasmacytoid dendritic cells from blood and tissues and better understand their origin and main functions. First, by sensing nucleic acid sequences via the TLR7/9-MyD88-IRF-7 pathway, plasmacytoid dendritic cells rapidly secrete large amounts of type I interferons (IFN-I) and, to a lesser extent, other cytokines, including IL-6, IL-8, IL-12, tumor necrosis factor- $\alpha,{ }^{2,15}$ as well as various pro-inflammatory chemokines. ${ }^{6}$ Although many cells can produce IFN-I, plasmacytoid dendritic cells are the fastest responder to INF-I inducers and the major cellular source of the cytokine (especially IFN-alpha). Other cytoplasmic nucleic acid sensors (eg, RIG-I, MDA5, LGP2, and DDX) expressed by various nucleated cells, including plasmacytoid dendritic cells, have been identified as triggers of IFN-I responses. ${ }^{16}$ Moreover, a set of surface activating (FCyRIIa and CD300a/c) and inhibitory (eg, BDCA2, ILT7, NKp44, and DCIR) receptors fine-tune the amplitude of IFN-I responses. ${ }^{17}$ Second, together with conventional myeloid dendritic cell subsets, plasmacytoid dendritic cells complete the contingent of human dendritic cells. Dendritic cells represent a heterogeneous population of antigen-presenting cells, found in blood and tissues, that are capable of initiating and fine-tuning immune responses to different pathogens, as well as contributing to immune tolerance. In addition to type I IFN-producing plasmacytoid dendritic cells, two myeloid dendritic cell populations have been identified in blood and peripheral tissues, namely the CD1C+(BDCA1+) dendritic cells and the CD141+(BDCA3+) dendritic cells. ${ }^{18}$ Their inclusion is based on the initial observation that plasmacytoid dendritic cells undergo profound morphological, phenotypical, and functional changes upon stimulation with CD40 ligand, interleukin-3, or a variety of microbial stimuli. ${ }^{3,19}$ This functional dichotomy may represent two evolutionary distinct states, where the production of IFN-I is lost upon differentiation into dendritic cells. ${ }^{20,21}$ Nevertheless, the term plasmacytoid dendritic cell has been adopted to encompass all states.

In vitro, plasmacytoid dendritic cells are capable of inducing CD4 and CD8 T-cell proliferation and Th1 polarization after infection or immunization. ${ }^{22}$ However, it is still unclear whether these immunological functions are relevant during various types of immune responses, ${ }^{22}$ once plasmacytoid dendritic cells migrate to diseased tissues. ${ }^{6}$ A tolerogenic role has been proposed for plasmacytoid dendritic cells in several systems, by induction of regulatory $\mathrm{T}$ cells. Tolerogenic plasmacytoid dendritic cells may be relevant in certain immune responses, however, a broad designation of steady-state plasmacytoid dendritic cells as tolerogenic would be misleading at the present time. ${ }^{23}$

On the basis of their efficient production of IFN-I and dendritic cell differentiation, plasmacytoid dendritic cells bridge the innate and acquired components of the immune responses, with documented roles in defense against pathogens, cancer, and autoimmunity. ${ }^{5,12,15,17,23,24}$ Interestingly, plasmacytoid dendritic cells may also exert direct effector functions. In particular, their activation via different stimuli might result in the release of TRAIL and Granzyme B.

Recently, progress has been made on the knowledge of plasmacytoid dendritic cell development. Plasmacytoid dendritic cells share with myeloid dendritic cells a unique developmental pathway from a common macrophage/dendritic cell progenitor. The initial development of these dendritic cell populations is controlled by Flt3L (Fms-like tyrosine kinase 3 ligand). ${ }^{25,26}$ Subsequently, the sustained upregulation of the basic helix-loop-helix transcription factor (E protein) E2-2 and SPI-B serve as a key signal for lineage commitment to plasmacytoid dendritic cells ${ }^{27}$ and for preservation of their cell fate, avoiding spontaneous plasmacytoid dendritic cells transformation into myeloid dendritic cells. Interestingly, while myeloid dendritic cell major subsets $\left(\mathrm{CD} 1 \mathrm{C}^{+}\right.$and $\left.\mathrm{CD} 141^{+}\right)$have a direct and immediate circulating precursor, plasmacytoid dendritic cells migrate from the bone marrow to the 

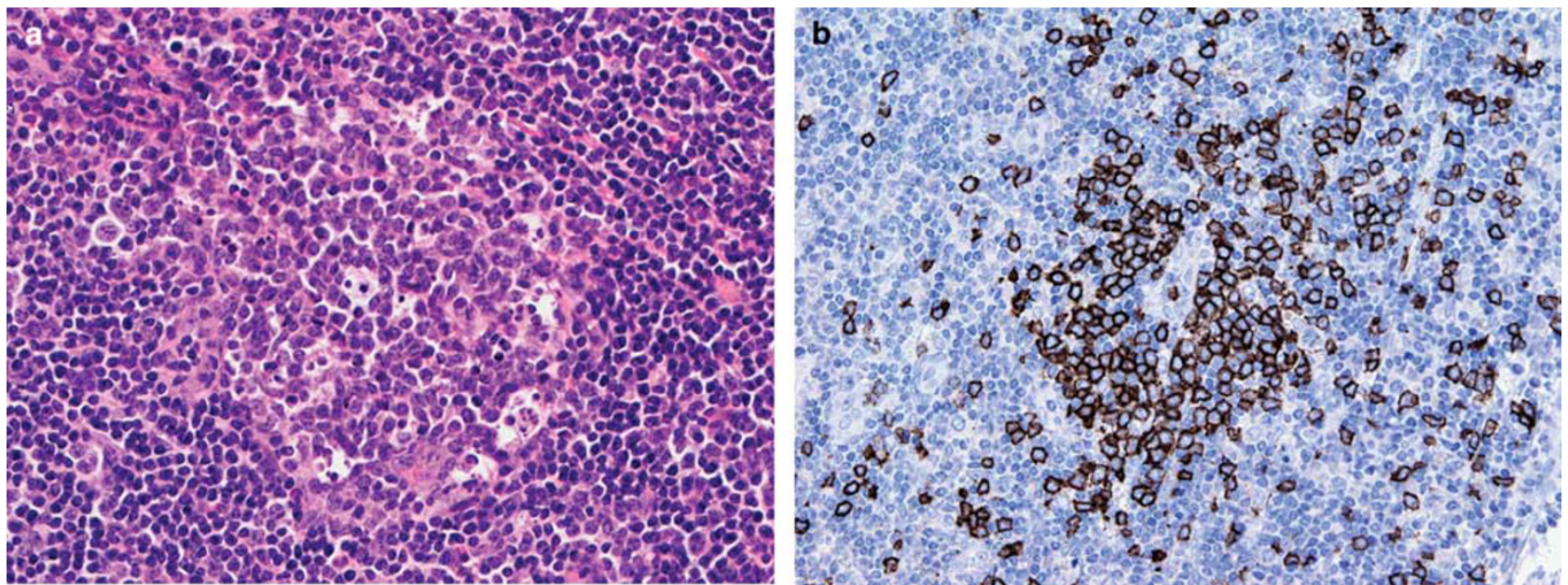

Figure 1 (a) Plasmacytoid dendritic cells nodule in a reactive lymph node, closely associated with high endothelial venules and containing macrophages with tingible bodies (hematoxylin and eosin stain). (b) Anti-CD303, the most specific marker for plasmacytoid dendritic cells, stains a cluster and surrounding scattered plasmacytoid dendritic cells.

blood and lymphoid tissues as fully differentiated cells. ${ }^{28}$

Numerous clinical and histological observations indicate a role for plasmacytoid dendritic cells in different disease states. The discovery of the murine plasmacytoid dendritic cell counterpart offered to challenge their specific requirement in diseases. This was significantly emphasized with the introduction of transgenic mice that express the diphtheria toxin receptor under the control of the BDCA2 promoter [Bdca2-DTR mice] ${ }^{29}$ resulting in transient and highly specific plasmacytoid dendritic cell depletion. These and other mouse models have significantly clarified the role of plasmacytoid dendritic cells during viral infections and autoimmunity. ${ }^{16,29,30}$ In particular, it has been demonstrated that plasmacytoid dendritic cells mediate early antiviral IFN-I responses, influencing the recruitment of virus-specific NK or CD8+ T cells in a virus-dependent manner. ${ }^{16,29,30}$ Similarly, in BXSB lupus-prone mice, plasmacytoid dendritic cells have a pivotal role in initiating the immune dysregulation and the pathological changes of lupus autoimmunity. ${ }^{16,29,30}$ These data may help extend knowledge on this cell type in human pathology.

\section{Distribution, morphology, and immunophenotype of normal plasmacytoid dendritic cells}

Circulating plasmacytoid dendritic cells are rare $(0.01-0.5 \%)$ and their number diminishes with age. ${ }^{31}$ In the peripheral blood, plasmacytoid dendritic cells are defined as CD11c-/CD123 +/CD303+ dendritic cells, opposed to CD11c +/CD123-/CD303 - myeloid dendritic cells. ${ }^{32,33}$ Heterogeneity in the level of expression of CD2,
CD5, CD7, CD33, or CD56 among normal circulating plasmacytoid dendritic cells ${ }^{34}$ may account for the phenotypic variability among tumoral plasmacytoid dendritic cell proliferations.

Plasmacytoid dendritic cells primarily reside in lymph nodes and tonsils, ${ }^{35,36}$ whereas they are rare in the thymic medulla, bone marrow, spleen, and mucosa-associated lymphoid tissue, and are nearly absent in peripheral non-lymphoid tissues. ${ }^{13}$ Within lymph nodes, a significant accumulation of plasmacytoid dendritic cells is generally related to an ongoing immune reaction, ${ }^{2}$ whereas recruitment of plasmacytoid dendritic cells to non-lymphoid tissues occurs during inflammatory ${ }^{4,5}$ or neoplastic diseases. ${ }^{5,6}$

Plasmacytoid dendritic cells are medium-sized cells with round-ovoid, sometimes elongated nucleus, showing fine chromatin and small but clearly distinct nucleoli; the cytoplasm stains eosinophilic with hematoxylin/eosin (Figure 1a), basophilic with Giemsa, and on electron-microscopy contains abundant rough endoplasmic reticulum. ${ }^{37}$ Nodal plasmacytoid dendritic cells are typically distributed close to high endothelial venules as clusters or dispersed cells. ${ }^{35}$ In other lymphoid tissues and in the bone marrow, plasmacytoid dendritic cells are scattered and never form aggregates. Their identification often requires immunostaining (Table 1); the most useful markers are CD123, BDCA2/CD303,4,38 (Figure 1b) and TCL1 (T-cell leukemia/lymphoma 1). ${ }^{39}$ Plasmacytoid dendritic cells express granzyme B, but not perforin and TIA-1; 40 they lack expression of lineage-specific antigens for B cells, $\mathrm{T}$ cells, natural killer cells, myeloid or monocytic cells (Table 1). The proliferation rate of plasmacytoid dendritic cells is low $(<1 \%)$ and CD34, CD117, and terminal deoxynucleotidyl transferase $(\mathrm{TdT})$ are negative. ${ }^{13,14,41,42}$ 
Table 1 Normal plasmacytoid dendritic cells immunophenotype

\begin{tabular}{|c|c|c|}
\hline & Positive on plasmacytoid dendritic cells & Negative on plasmacytoid dendritic cells \\
\hline B-cell antigens & 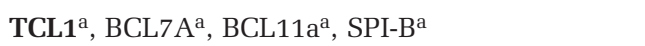 & CD19, CD20, CD22b , CD79a, PAX5, sIg, cIg \\
\hline T-cell antigens & CD4 & $\begin{array}{l}\text { CD2 }^{\mathrm{c}} \text {, CD3, CD5 }{ }^{\mathrm{c}}, \mathrm{CD}^{\mathrm{c}} \text {, CD8, CD103, LAT, T-bet, } \\
\text { TCR-AB, TCR-GD, ZAP70 }\end{array}$ \\
\hline $\begin{array}{l}\text { NK/cytotoxic cells } \\
\text { antigens }\end{array}$ & Granzyme B & CD16, CD56' , perforin, TIA-1 \\
\hline \multirow{3}{*}{$\begin{array}{l}\text { Myeloid/monocytic/ } \\
\text { dendritic cells antigens }\end{array}$} & CD36, CD68 & CD11b, CD11c, CD13, CD14, CD15, CD33 , CD163, \\
\hline & $\begin{array}{l}\text { BDCA2/CD303 }^{\mathrm{d}} \text {, } \\
\text { BDCA-4/CD304 }\end{array}$ & $\begin{array}{l}\text { DC-LAMP/CD208, elastase, esterases, langerin/CD207, } \\
\text { lysozyme, myeloperoxidase, mannose receptor/CD206, } \\
\text { DC-SIGN/CD209 }\end{array}$ \\
\hline & & CD1c/BDCA1, CD141/BDCA3 \\
\hline Miscellaneous antigens & CD11a, CD31, CD32, CD40, CD43, CD44, CD45RA, & CD1a, CD10, CD21, CD23, CD25, CD27, CD28, CD30, \\
\hline & CD45RB, CD49e, CD62L, CD71, CD74, CD123, & CD34, CD35, CD38, CD45R0, CD57, CD64, CD65, CD80, \\
\hline & CD128, BAD-LAMP, CLA/CD162, CD2AP, & CD83, CD86, CD94, CD95, CD117, CD125, CD138, \\
\hline & E-cadherin, HLA-ABC, HLA-DP, HLA-DQ, HLA- & CDw150, CD161, BCL2, BCL6, FOXP3, ILT3, \\
\hline & $\begin{array}{l}\text { DR, MxA, TLR1/CD281, TLR6/CD286, TLR7/287, } \\
\text { TLR9/CD289, TLR10/290 }\end{array}$ & $\begin{array}{l}\text { MUM1/IRF4, S100, TdT, TLR2/CD282, TLR3/CD283, } \\
\text { TLR4/CD284, TLR5/CD285, TLR8/CD288 }\end{array}$ \\
\hline
\end{tabular}

Abbreviations: LAT, linker for activation of T cell; TCR, T-cell receptor; TLR, Toll-like receptor.

aThese markers also stain normal B cells: TCL1, mantle and germinal center cells; BCL7A, germinal center, some mantle and interfollicular B cells;

SPI-B, germinal center cells; BCL11a: mantle, germinal center and marginal zone cells.

$\mathrm{b}_{\mathrm{A}}$ positive immunoreactivity has been demonstrated only with the anti-CD22 s-HCL-1 monoclonal antibody.

${ }^{\mathrm{C}}$ These markers may be variably or weakly expressed on normal circulating plasmacytoid dendritic cells.

dunique for plasmacytoid dendritic cells.

Markers particularly useful to identify plasmacytoid dendritic cells on paraffin sections are reported in bold.

\section{Mature plasmacytoid dendritic cell proliferation associated with myeloid neoplasms}

This tumoral condition involving plasmacytoid dendritic cells was originally described in 1983 and reported as plasmacytoid T-cell lymphoma. ${ }^{10}$ About 80 cases of this lesion have been reported as single reports or small series. ${ }^{43-48}$ Patients are predominantly males $(75 \%)$, and the median age is 69 years, but rare cases have been reported in young individuals, including a 6-year-old girl. Most patients are affected by chronic myelomonocytic leukemia or, more rarely, myelodysplasia and acute leukemias with monocytic differentiation; no association with chronic myelogenous leukemia has been reported. ${ }^{43,45,48}$ The clinical manifestations directly attributable to plasmacytoid dendritic cell accumulation predominantly consist of lymphadenopathy and skin lesions (multiple erythematous macules or papules), whereas splenomegaly is rare. ${ }^{13,45,46,49}$ Plasmacytoid dendritic cells are often identified in bone marrow biopsies, whereas circulating plasmacytoid dendritic cells are very rarely found. ${ }^{44}$ The infiltrates of plasmacytoid dendritic cells consist of nodules or irregular aggregates composed of cells morphologically similar to normal plasmacytoid dendritic cells, although the nuclear contour is often irregular. These nodules can be numerous, sometimes confluent, and may show prominent apoptosis (Figure 2a and b). Occasionally, a perinodular rim composed of cells with abundant pale cytoplasm and irregular nuclei, phenotypically corresponding to interdigitating dendritic cell (S100 and CD1a positivity) may occur. ${ }^{43,45}$ When plasmacytoid dendritic cells co-localize with the myeloid leukemia, they can be promptly recognized by morphology and, especially, by phenotyping. ${ }^{43,44,47}$ Plasmacytoid dendritic cells substantially show the same antigen profile of the reactive counterpart, with occasional aberrant expression of CD2, CD5, CD7, CD10, CD13, CD14, CD15, and CD33. ${ }^{41,43,45,46,49}$ CD56 expression is negative in most of the cases, or focal and weak reactivity may be observed (Figure 2c-f). ${ }^{40,45}$ Plasmacytoid dendritic cells have a low proliferation index $(<10 \%$ Ki-67) and lack TdT and CD34 (Table 2).

The genomic landscape of this entity is poorly understood. The neoplastic nature of plasmacytoid dendritic cells and their relatedness with the associated myeloid neoplasm has been suggested in several cases by fluorescence in situ hybridization, showing the occurrence of similar and clonal chromosomal abnormalities in the two cellular components. ${ }^{43,44,47}$

Treatment of the underlying myeloid neoplasm may result in the regression of the plasmacytoid dendritic cells infiltrates. ${ }^{43,45,50}$ Prognosis is usually dismal (median survival: 11 months; range 0-84 months), and reflects the evolution of the myeloid leukemia rather than a progressive expansion of plasmacytoid dendritic cells. In Vitte's series of 16 patients with dermatological presentation, $45 \%$ died of disease (median survival: 9 months; range: 2-23 months), whereas $52 \%$ were alive with a median overall survival from onset of skin manifestations of 21 months (range: 3-69 months).

Although abnormal accumulations of plasmacytoid dendritic cells may occur in reactive lymph nodes and skin in Kikuchi's lymphadenitis, 
Castleman's hyaline-vascular disease and lupus erythematosus, ${ }^{13}$ the presence of extensive nodules of plasmacytoid dendritic cells within tissues should prompt to carefully evaluate the hematological status of the patient to exclude a myeloid neoplasm. ${ }^{51}$
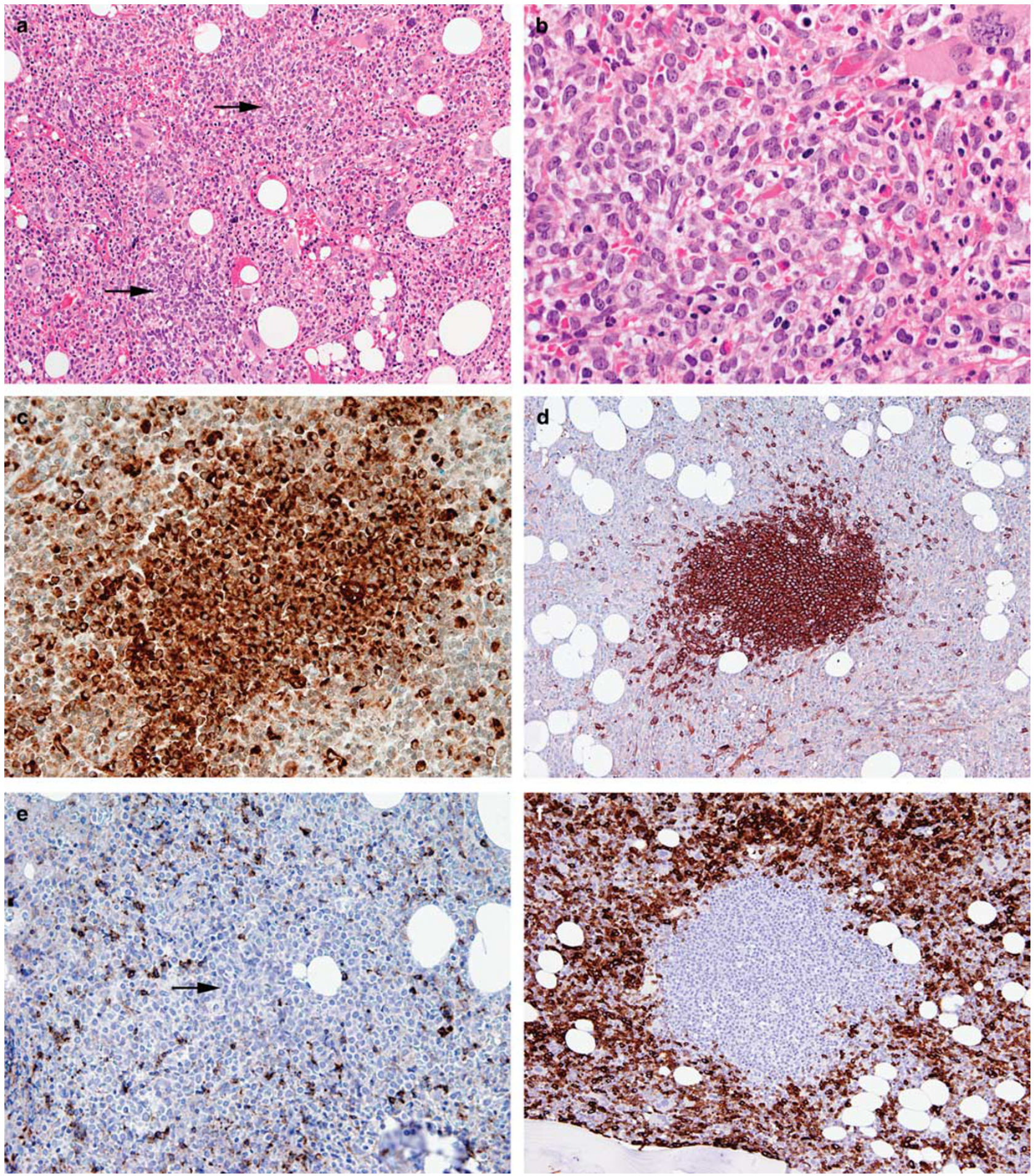

Figure 2 Examples of cases of 'Mature plasmacytoid dendritic cells proliferation associated with myeloid neoplasms'. A bone marrow biopsy in a case of idiopathic myelofibrosis contains two plasmacytoid dendritic cells nodules (a, arrows); plasmacytoid dendritic cells show features similar to those of reactive plasmacytoid dendritic cells, with some nuclei having irregular contours (b). Positive and negative immunohistochemical stains on plasmacytoid dendritic cells nodules involving a lymph node (c) or bone marrow (d-f); plasmacytoid dendritic cells are strongly reactive for CD68 (c) and CD123 (d), whereas they are negative for CD56 (e, arrow) and myeloperoxidase (f). 
Table 2 Comparison of immunohistochemical markers expression between mature and immature plasmacytoid dendritic cell tumors

\begin{tabular}{|c|c|c|}
\hline & $\begin{array}{l}\text { Mature plasmacytoid dendritic cell } \\
\text { proliferation associated with myeloid } \\
\text { neoplasms }\end{array}$ & $\begin{array}{l}\text { Blastic plasmacytoid dendritic cell } \\
\text { neoplasm }\end{array}$ \\
\hline $\begin{array}{l}\text { Expression similar to normal plasmacytoid } \\
\text { dendritic cells }\end{array}$ & $\begin{array}{l}\text { CD4, CD68, CD123, CD303/BDCA2, CD2AP, } \\
\text { CLA/CD162, TCL1, Granzyme B }\end{array}$ & $\begin{array}{l}\text { CD43, HLA-DR, CD45RA } \\
\text { CD4, CD36, CD123, CD303/BDCA2, } \\
\text { CD304/BDCA-4, ILT3, CD2AP, TCL1, SPI-B }\end{array}$ \\
\hline $\begin{array}{l}\text { Negative/abnormal expression compared to } \\
\text { reactive plasmacytoid dendritic cells }\end{array}$ & $\begin{array}{l}\text { No loss of normal plasmacytoid dendritic } \\
\text { cells markers }\end{array}$ & $\begin{array}{l}\text { CD68 (negative or single paranuclear dot) } \\
\text { CLA/CD162 (negative or single paranuclear } \\
\text { dot) } \\
\text { Granzyme B (negative) }\end{array}$ \\
\hline De novo expression & $\begin{array}{l}\text { Occasional: } \\
\text { CD2, CD5, CD7, CD10, CD13, CD14, CD15, } \\
\text { CD33, CD56 (weak/focal) }\end{array}$ & $\begin{array}{l}\text { Frequent: } \\
\text { CD56, CD7, CD33, TdT (30\%) } \\
\text { Occasional: } \\
\text { CD2, CD3, CD13, CD5, CD10, CD38, CD117, } \\
\text { MUM1/IRF4, BCL2, BCL6, S100 }\end{array}$ \\
\hline
\end{tabular}

\section{Blastic plasmacytoid dendritic cell neoplasm}

The remainder of this review will focus on blastic plasmacytoid dendritic cell neoplasm. Blastic plasmacytoid dendritic cell neoplasm consists of clonal proliferation of plasmacytoid dendritic cells precursors. Previously known under different names owing to the uncertainty of its histogenesis (eg, agranular $\mathrm{CD}^{+}$natural killer (NK) cell leukemia, ${ }^{52}$ blastic NK-cell leukemia/lymphoma, ${ }^{53}$ agranular $\mathrm{CD}^{+}{ }^{+}, \mathrm{CD} 6^{+}$hematodermic neoplasm ${ }^{34}$ or tumor, ${ }^{54}$ and blastic NK-cell lymphoma ${ }^{55}$ ), a relationship to plasmacytoid dendritic cells was first hypothesized by Lucio et $a l^{56}$ and subsequently supported by phenotypic, ${ }^{34,39,41,57-65}$ molecular, ${ }^{57,66}$ and functional data, ${ }^{58,67}$ including the ability of tumor cells to produce IFN-I $57,58,64$ and to differentiate into dendritic cells. ${ }^{57,58,68}$ In blastic plasmacytoid dendritic cell neoplasm patients, cell lines generated from the circulating neoplastic component recapitulate to a large extent the biological properties of plasmacytoid dendritic cells. ${ }^{68-70}$ The term blastic plasmacytoid dendritic cell neoplasm was introduced in 2008 in the updated WHO classification. ${ }^{11}$

Blastic plasmacytoid dendritic cell neoplasm is rare and its exact incidence is unknown. There is no racial or ethnic predominance. ${ }^{42}$ From a review of 665 cases (included in 179 studies, in addition to 30 unpublished cases from the author's files), $74 \%$ of blastic plasmacytoid dendritic cell neoplasms occurred in males (M/F: 3/1) and most patients were adults, with a mean/median age at diagnosis of 58/65 years (range 0-96), that is lower in females (50/58 versus 61/67). Interestingly, only males show marked variation of distribution during decades with a significant incidence peak in the sixth and seventh decades. About $5 \%$ of blastic plasmacytoid dendritic cell neoplasms occur in patients younger than 10 years.

\section{Clinical presentation}

The clinical features and evolution of blastic plasmacytoid dendritic cell neoplasm are rather homogeneous among different series ${ }^{42,52-54,62,71-77}$ and consist of two main patterns, the 'dermatopathic' (more than $90 \%$ of cases), characterized by a deceptive indolent onset dominated by skin lesions followed by tumor dissemination, and the 'leukemic', with acute leukemia and systemic involvement since the beginning.

The striking cutaneous tropism of blastic plasmacytoid dendritic cell neoplasm tumor cells has been attributed to their expression of antigens that favor skin migration, such as CLA and CD56, and to the local availability of chemokines binding cognate receptor expressed by neoplastic plasmacytoid dendritic cells (CXCR3, CXCR4, CCR6, CCR7). ${ }^{67}$ Skin lesions are often multiple; they can involve any body site as nodules, plaques, or bruise-like areas, with heterogeneous color (erythematous, reddish, or bluish) and size (from few millimeters to several centimeters; Figure 3a). ${ }^{42,76,77}$ Skin lesions are the only detectable clinical manifestation in about $50 \%$ of cases. ${ }^{54,71,77}$ A localized or generalized lymphadenopathy is common at presentation $(\sim 40 \%$ of cases), as well as spleen (25\%), and liver (16\%) enlargement. ${ }^{42,54,77}$ Mucosal lesions, especially involving the oral cavity, have been described more rarely. ${ }^{77}$ Bone marrow involvement at onset occurs in 50 to $90 \%$ of cases. Although it may be negligible and demonstrable only by immunohistochemistry, ${ }^{78}$ it invariably becomes more manifest with progression of the disease. Anemia and thrombocytopenia are frequently observed at diagnosis, and in a minority of cases are severe. ${ }^{54,79}$ Peripheral blood involvement occurs in about half of the patients, generally with an initial low number of blasts (median, $2 \%$; range, 0 to $94 \%$ ). ${ }^{72,79-81}$

The 'leukemic' variant is characterized by an elevated white blood cell count, circulating blasts, and massive bone marrow infiltration. ${ }^{79,81-84}$ Generally, multiple skin lesions are also present. ${ }^{72}$ 
From the review of 756 cases of blastic plasmacytoid dendritic cell neoplasm, 49 (7\%) showed a 'pure' leukemic presentation, that occurred mainly in males $(\mathrm{M} / \mathrm{F}=2.1)$, with a mean/median age at diagnosis of 52/61 years (ranging from 8 to 86 years). Peripheral blood and marrow blasts were observed
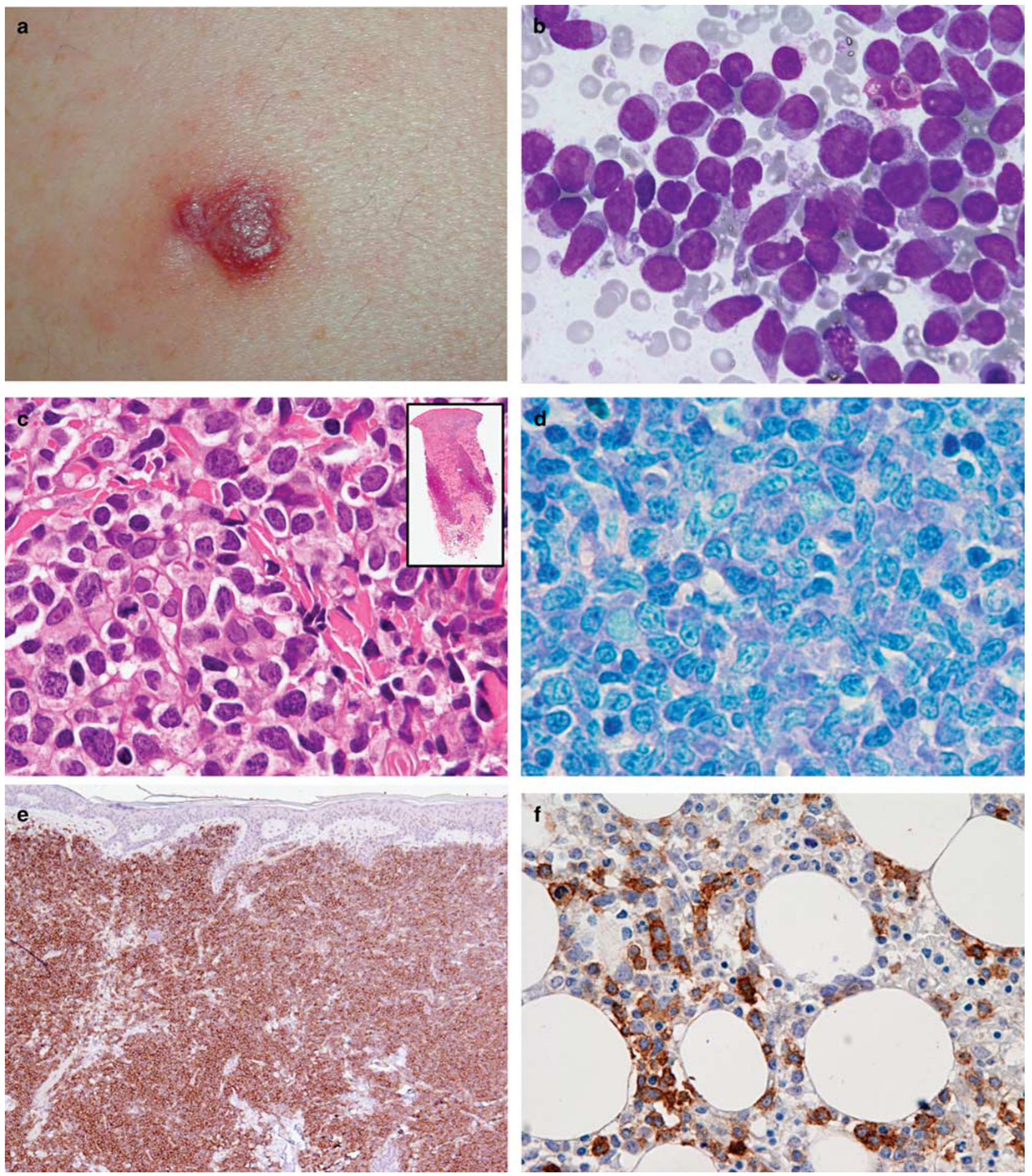

Figure 3 Examples of cases of blastic plasmacytoid dendritic cell neoplasm. Skin manifestation of blastic plasmacytoid dendritic cell neoplasm in the form of reddish, non-ulcerated nodule (a). Cytomorphology of blastic plasmacytoid dendritic cell neoplasm in a bone marrow aspirate showing immature tumor cells, resembling either myeloblasts or lymphoblasts; some plasmacytoid dendritic cells have pseudopodia-like extension of the cytoplasm (b). (c) A skin biopsy with extensive dermal infiltrate (inset); tumor cells exhibit blastic undifferentiated morphology with scant eosinophilic cytoplasm (c), that stains pale blue on Giemsa (d). CD303 is strongly expressed by blastic plasmacytoid dendritic cell neoplasm involving the skin (e) and can be useful to detect minimal infiltrate in the bone marrow (f). 
in 32 and $78 \%$ of the patients, respectively, whereas splenomegaly and lymphadenopathy were reported in $15(30 \%)$ and $23(47 \%)$ cases, respectively.

Rare cases of blastic plasmacytoid dendritic cell neoplasm are associated with another myeloid neoplasm, that may precede, concur, or follow blastic plasmacytoid dendritic cell neoplasm. This condition was reported in 43 out of 756 blastic plasmacytoid dendritic cell neoplasm reviewed cases $(6 \%)$, and consisted of acute myeloid leukemia (10 cases), chronic myeloid leukemia (two cases), chronic myelomonocytic leukemia (six cases), 'subacute myelomonocytic leukemia' (one case) and myelodysplasia $\quad(20$ cases $) .36,39,45,54,57,60,62,76,79,83,85,86$ Myeloid leukemic cells are phenotypically distinct from blastic plasmacytoid dendritic cell neoplasm tumor cells, but can share CD4 and CD56, as well as TCL1 and CD123, suggesting that the two diseases may have a common origin.

\section{Morphology}

The blastic plasmacytoid dendritic cell neoplasm is composed of monomorphic, medium-sized tumor cells, with obvious blastic features resembling either lymphoblasts or myeloblasts. Nuclei display irregular contour and fine chromatin; nucleoli, when present, are eosinophilic, and may be single or multiple. The cytoplasm is usually scant and appears gray-blue, devoid of cytoplasmic azurophilic granules on Giemsa stain (Figure 3c and d). Mitoses are regularly found and Ki-67-positive cells vary from 20 to $80 \% .64,76,85,87$

In the skin, the dermis is usually massively involved with extension to the subcutaneous fat; the epidermis and adnexa are spared, with rare exceptions. ${ }^{76}$ Low-density infiltrates are generally superficially located and may mimic inflammation. As typically found in secondary lymph node involvement by leukemias, tumor cells permeate the interfollicular areas and the medulla but spare B-cell follicles. Bone marrow blasts may vary from sparse to diffuse and confluent. ${ }^{71}$ On blood and marrow smears, tumor cells may show cytoplasmic microvacuoles and pseudopodia-shaped expansions; granules or crystals are regularly absent (Figure 3b). ${ }^{79}$

\section{Immunophenotype}

The diagnosis of blastic plasmacytoid dendritic cell neoplasm requires immunophenotyping and fundamentally relies on the demonstration of CD4, CD56, CD123, CD303, and TCL1 expression, together with lack of expression of markers for B cells, T cells, myeloid or monocytic cells, and NK cells (Table 2). Exceptions include CD5, CD7, and CD33, which may be positive in some cases, and cytoplasmic CD3, which has been rarely reported using polyclonal anti-CD3-epsilon antibodies.

Typically, the blastic plasmacytoid dendritic cell neoplasm is positive for CD4 and CD56 expression. ${ }^{34,42,73,74,76,79,87-89}$ Among 565 reviewed cases in which staining for CD4 and CD56 was applied, 92\% were CD4+CD56+, while the remaining showed lack of either antigens $(8 \%)$ and one case only $(0.2 \%)$ was double negative. As expression of CD4 and CD56, singly or in association, can be observed in several other hematological diseases, a definite diagnosis of blastic plasmacytoid dendritic cell neoplasm requires the demonstration of more plasmacytoid dendritic cell-specific antigens. A literature search of blastic plasmacytoid dendritic cell neoplasm series and case reports revealed that staining for CD4, CD56, CD123, and TCL1 has been applied to 237 cases; all of these markers were positive in 189/237 (80\%), while CD4+CD56+CD123+ or CD4+CD56+TCL1+ expression were found, respectively, in 206/237 (87\%) and 195/244 (80\%) cases. Use of anti-CD303 monoclonal antibody, recognizing the BDCA2 antigen, currently represents the most specific marker for normal and neoplastic plasmacytoid dendritic cells (Figure 3e and f). ${ }^{33,36,38,90}$ Staining for this marker showed variable expression in blastic plasmacytoid dendritic cell neoplasm in different series, probably depending on the nature and quality of the reagent used or on the substrate (fresh-frozen versus formalin-fixed tissue) used. ${ }^{38,42,45,49,60,63,64,87,90}$ Among 120 reported cases using anti-CD303 antibodies, 95 $(79 \%)$ resulted positive.

In conclusion, at present, even though no consensus has been established with regard to a minimal phenotype to diagnose blastic plasmacytoid dendritic cell neoplasm by immunohistochemistry, a confident diagnosis can be made when four antigens among CD4, CD56, CD123, TCL1, and CD303 are expressed by neoplastic cells. ${ }^{38,87,91}$ Remarkably, in addition to CD56, blastic plasmacytoid dendritic cell neoplasm may express antigens that are usually negative in normal plasmacytoid dendritic cells, such as BCL2, BCL6, MUM1, ${ }^{76}$ CD38, ${ }^{34,79}$ and S100 protein. ${ }^{36,62,86,90}$ Blastic plasmacytoid dendritic cell neoplasm express terminal deoxynucleotidyl transferase in about one-third of the cases, with positivity ranging from 10 to $80 \%$ of tumor cells. ${ }^{34,41,53,73,74,89}$ Interestingly, terminal deoxynucleotidyl transferase and either CD303 (ref. 63) or S100 protein ${ }^{87}$ can be expressed in a mutually exclusive pattern by tumor cells. CD117 can be positive, while CD34 has mostly been reported negative. ${ }^{57,60,71,73,81,86}$ However, a recent study has demonstrated that a subset of blastic plasmacytoid dendritic cell neoplasms are negative for CD56, but express CD34 in a fraction of blast cells, suggesting the existence of different maturation stages of this tumor. ${ }^{92}$

According to the WHO, tumors which share some but not all immunophenotypic features of blastic 
plasmacytoid dendritic cell neoplasm may be better classified as 'acute leukemia of ambiguous lineage' ${ }^{11}$

By flow cytometry, tumor cells occur in the low-side scatter blast-gate with dim expression of CD45. ${ }^{57,61,81,88,92,93}$ The lack of lineage-associated antigens, together with a high-intensity expression of CD123, positivity for HLA-DR, CD4, CD45RA, and CD56, has been considered a unique and virtually pathognomonic phenotype for blastic plasmacytoid dendritic cell neoplasm. ${ }^{79,81,88}$

Garnache-Ottou et $a l^{93}$ evaluated a large series of markers by flow cytometry on 20 cases of blastic plasmacytoid dendritic cell neoplasm and 113 lymphoid and myeloid acute leukemias. High levels of expression of CD123 based on mean fluorescence intensity ratio were identified in all cases of blastic plasmacytoid dendritic cell neoplasm and in only two acute myeloid leukemias. A low expression of this antigen, however, was commonly found in most acute leukemias. BDCA2/CD303 was expressed on 14/20 blastic plasmacytoid dendritic cell neoplasms, but was never detected in the 113 lymphoid or myeloid leukemia cases. On the basis of their results, the authors defined a scoring system for blastic plasmacytoid dendritic cell neoplasm diagnosis that required a total score higher than 2, among four parameters represented by (a) expression of CD4 (not necessarily CD56) with negativity of myeloperoxidase, cCD3, cCD79a, and CD11c (score 1); (b) positivity of CD123 (score 1); (c) BDCA2/CD303 (score 2); and (d) BDCA-4/CD304 (score 1). Four cases of blastic plasmacytoid dendritic cell neoplasm showing a score as high as the 'classical' type associated with the expression of CD10 and CD117 (one case), CD10 (1), CD22 (1), or TdT (1) were defined as 'atypical'.

\section{Genetic and molecular findings}

T-cell and B-cell receptor genes are typically in a germline configuration. ${ }^{62,71,74}$ The rare cases showing $\mathrm{T}$-cell receptor gamma rearrangement may be owing to clonal by-stander T cells. ${ }^{54,71,91}$

No specific karyotypic abnormalities are found in blastic plasmacytoid dendritic cell neoplasm, but complex chromosomal aberrations often occur, with six major recurrent chromosomal targets, represented by $5 q(72 \%), 12 p(64 \%)$, 13q $(64 \%)$, $6 q$ (50\%), $15 \mathrm{q}(43 \%)$, and $9(28 \%) .{ }^{94}$ Although in a limited number of cases owing to the rarity of the disease, the genomic landscape of blastic plasmacytoid dendritic cell neoplasm has been investigated by using different molecular techniques. On the basis of cumulative data obtained by different groups, the profile includes either a fraction of known variants found in other myeloid neoplasms as well as deleterious mutations previously unreported in human leukemia. Frequent genomic loss involving tumor suppressor genes or genes related to the G1/S transition have been reported, ${ }^{62,66,73,91,94-98}$ the most recurrent being represented by deletions of $C D K N 2 \mathrm{~A}$ (27\% of cases). ${ }^{98}$

TET2 is the most common mutated gene (36 to $80 \%$ of cases) in blastic plasmacytoid dendritic cell neoplasm, as originally found by Jardin et $a l^{97}$ and subsequently confirmed by next-generation sequencing analysis, ${ }^{91,99}$ suggesting that this gene may have a role in tumor pathogenesis. Targeted sequencing identified deleterious mutations of IKZF3 and ZEB2 genes (12-16\%), previously unreported in human leukemia, ${ }^{99}$ as well as recurrent somatic mutations commonly found in other myeloid neoplasms, such as $\operatorname{ASXL1}(32 \%)$, NPM1 (10\%), and RAS family genes (9 to $27 \%$ ), the latter recurring in a mutually exclusive distribution. ${ }^{91,98,99}$ Overall, genes mutated in blastic plasmacytoid dendritic cell neoplasm affect proteins involved in DNA methylation, chromatin remodeling, and transcription.

Gene expression profiling of blastic plasmacytoid dendritic cell neoplasm showed a unique signature, distinct from myeloid and lymphoid acute leukemias. ${ }^{66,100}$ Compared with normal plasmacytoid dendritic cells, blastic plasmacytoid dendritic cell neoplasm samples showed increased expression of genes involved in Notch signaling ${ }^{66}$ and NFKB activation, ${ }^{100}$ the latter representing a potential therapeutic target. ${ }^{100}$

\section{Clinical course and treatment}

Even though the clinical presentation of blastic plasmacytoid dendritic cell neoplasm may be indolent, the disease invariably progresses and prognosis remains poor, with a median overall survival ranging from 9 to 20 months. ${ }^{42,54,71,75-77,79,80,82,83}$

The identification of prognostic factors is difficult owing to rarity of blastic plasmacytoid dendritic cell neoplasm and to the wide range of different treatments used. Age has an adverse impact on survival, ${ }^{72,75}$ and long-term survival has been reported in $36 \%$ of pediatric patients in a retrospective series. ${ }^{90}$ Skin involvement at diagnosis has a controversial effect. In a pediatric series, clinical outcome was more favorable in patients lacking cutaneous lesions at presentation, ${ }^{90}$ while in adults the occurrence of skin lesions was associated with a significant prognostic advantage in some studies, ${ }^{72,75,82}$ but not in others ${ }^{80,101}$ High marrow or peripheral blood blastosis worsen prognosis, ${ }^{72}$ as also shown by the short median overall survival (10 months) that we observed in 49 patients from different series, who presented with overt leukemia without skin lesions.

Among biological parameters, low TdT expression, ${ }^{63,72,75}$ positivity for BDCA2/CD303, ${ }^{63}$ $C D K N 2 A / C D K N 2 B$ deletions, ${ }^{96}$ and mutations in DNA methylation pathway genes ${ }^{99}$ have been associated with reduced survival.

Treatment of blastic plasmacytoid dendritic cell neoplasm is not standardized. Complete remission may be achieved with local treatment in cases with 
isolated skin presentation, or after aggressive induction therapy with leukemia-oriented programs, but the rate of relapse is so high that consolidation with high-dose therapy is mandatory, with the possible exception of pediatric patients treated with acute lymphoblastic leukemia-like protocols. ${ }^{90}$ In a recent retrospective series, ALL-oriented induction treatment seemed more effective than AML-oriented therapy, ${ }^{83}$ despite plasmacytoid dendritic cells being closer to the myeloid rather than to the lymphoid lineage and that association of blastic plasmacytoid dendritic cell neoplasm with myeloid leukemias has been described in some cases. Complete remission was achieved in $67 \%$ of the cases, and median survival was 12 months in 15 patients after an acute lymphoblastic leukemia-oriented treatment. Corresponding figures in 26 patients receiving an acute myeloid leukemia-oriented treatment were significantly inferior, with a complete remission rate of $27 \%$ and median survival of 7 months. ${ }^{83}$

Intrathecal prophylaxis should be considered given the reported $33 \%$ frequency of central nervous system relapse. ${ }^{79}$ In patients in first complete remission, allogeneic transplantation has been advocated as the best way to obtain long-term survival, ${ }^{84,102}$ even in elderly patients using reduced-intensity conditioning. ${ }^{103}$ Registry data from 34 patients from the European Group for Blood and Marrow Transplantation showed a 3-year cumulative overall survival of $41 \% .102$ However, the contribution of graft versus malignancy effects to the control of blastic plasmacytoid dendritic cell neoplasm is still unclear and the efficacy of autologous transplant when performed in first complete remission has been also reported in a small registry series from Japan where a 4-year overall survival of $82 \%$ was obtained. ${ }^{104}$ Promising data were recently reported using the immunotoxin SL-101 targeting the interleukin-3 receptor alpha (CD123), ${ }^{105,106}$ which is generally overexpressed by plasmacytoid dendritic cell blasts and may be targeted also by bi-specific antibodies, chimericantigen receptor-modified $\mathrm{T}$ lymphocytes, or humanized monoclonal antibodies. Agents targeting the $\mathrm{NF}-\kappa \mathrm{B}$ pathway aberrantly activated in blastic plasmacytoid dendritic cell neoplasm ${ }^{100}$ or epigenetic treatments ${ }^{107}$ could also be rationally explored to ameliorate the still dismal prognosis of most blastic plasmacytoid dendritic cell neoplasm patients.

\section{Differential diagnosis}

A skin or bone marrow biopsy represents the first diagnostic procedure in most of the cases, and the differential diagnosis is primarily represented by acute non-lymphoid or lymphoid leukemias. Remarkably, $\mathrm{CD}^{+} \mathrm{CD}^{2} 6^{+}$co-expression can be observed in cases of acute myeloid leukemia, especially with monocytic differentiation, ${ }^{45,59,66,74,75}$ while it is infrequent in lymphoblastic leukemias.
Furthermore, CD123 and more rarely TCL1 can be found in myeloid leukemias. ${ }^{34,46,59,74}$ BDCA2/CD303 expression virtually excludes leukemias of all nonplasmacytoid dendritic cells ${ }^{38}$ while the expression of markers for myeloblasts (CD13, myeloperoxidase), monoblasts (CD11c, CD14, lysozyme), and B and T lymphoblasts (CD19, PAX5, CD3, LAT) is not consistent with blastic plasmacytoid dendritic cell neoplasm. Although infrequently, mature and blastic plasmacytoid dendritic cell neoplasms may show similar extensive involvement of tissues, especially lymph nodes; their distinction is primarily based on the evaluation of the cytological features (mature versus immature), the immunophenotype (Table 2) and the proliferation index.

\section{Summary and conclusions}

Plasmacytoid dendritic cell-derived tumoral proliferations are rare and include two main clinicopathological entities, likely corresponding to the clonal expansion of plasmacytoid dendritic cells or their immediate precursors. Specifically, neoplasms derived from fully differentiated plasmacytoid dendritic cells are regularly associated with another myeloid neoplasm that dominates the clinical course and guides the treatment program course ('Mature plasmacytoid dendritic cells proliferation associated with myeloid neoplasms'). The clonal nature of this proliferation of plasmacytoid dendritic cells and its relatedness to the associated myeloid neoplasia have been definitely established. On the other hand, the highly aggressive "blastic plasmacytoid dendritic cell neoplasm', derived from plasmacytoid dendritic cell precursors, has a distinctive cutaneous tropism followed by rapid systemic dissemination. The complex genomic landscape of blastic plasmacytoid dendritic cell neoplasm has been documented in limited series and it includes known variants found in other myeloid neoplasms and, remarkably, also mutations on genes unknown to affect the leukemogenesis.

For a correct definition of blastic plasmacytoid dendritic cell neoplasm, a complex panel of markers is mandatory. The triple-positive CD4+CD56+CD123+ phenotype combined with negativity for lineagespecific markers should represent a minimum requirement for blastic plasmacytoid dendritic cell neoplasm definition. The inclusion of the highly specific marker BDCA2/CD303, as well as other plasmacytoid dendritic cell-associated antigens (eg, TCL1 and CD2AP), might be of great support to rule out mimickers (acute myeloid leukemia, precursor lymphoblastic T-cell leukemia/lymphomas).

The long-term prognosis of blastic plasmacytoid dendritic cell neoplasm is dismal. However, a more sustained clinical remission or even definitive cure can be obtained with acute leukemia-oriented programs, followed by transplantation. Promising preclinical and clinical results have been obtained in 
blastic plasmacytoid dendritic cell neoplasm by targeting surface receptors with immunotoxins (ie, interleukin-3 receptor alpha) or inhibitors of aberrantly activated survival pathways (ie, NF- $\kappa$ B). Along the same line, and based on the genomic landscape of blastic plasmacytoid dendritic cell neoplasm, mechanistic studies will likely unveil new driver events underlying the transformation of plasmacytoid dendritic cells and blastic plasmacytoid dendritic cell neoplasm progression, and may thus pave the way to new therapeutic options.

\section{Acknowledgments}

This study is partially supported by M.I.U.R. (Italian Ministry of Education, University and Research) to FF (grant no. 20104HBZ8E_002). We are grateful to Professor Luigi D Notarangelo (Professor of Pediatrics and Pathology, Harvard Medical School) for helpful discussion.

\section{Disclosure/conflict of interest}

The authors declare no conflict of interest.

\section{References}

1 Lennert K, Remmele W. Karyometrische Untersuchungen an Lymphknotenzellen des Menschen: I. Mitt. Germinoblasten, Lymphoblasten und Lymphozyten. Acta Haematol (Basel) 1958;19:99-113.

2 Cella M, Jarrossay D, Facchetti F et al. Plasmacytoid monocytes migrate to inflamed lymph nodes and produce large amounts of type I interferon. Nat Med 1999;5:919-923.

3 Grouard G, Rissoan MC, Filgueira L et al. The enigmatic plasmacytoid T cells develop into dendritic cells with interleukin (IL)-3 and CD40-ligand. J Exp Med 1997;185:1101-1111.

4 Vermi W, Lonardi S, Morassi M et al. Cutaneous distribution of plasmacytoid dendritic cells in lupus erythematosus. Selective tropism at the site of epithelial apoptotic damage. Immunobiology 2009;214:877-886.

5 Vermi W, Soncini M, Melocchi L et al. Plasmacytoid dendritic cells and cancer. J Leukoc Biol 2011;90: 681-690.

6 Sozzani S, Vermi W, Del Prete A et al. Trafficking properties of plasmacytoid dendritic cells in health and disease. Trends Immunol 2010;31:270-277.

7 Asselin-Paturel C, Boonstra A, Dalod M et al. Mouse type I IFN-producing cells are immature APCs with plasmacytoid morphology. Nat Immunol 2001;2: 1144-1150.

8 Bjorck P. Isolation and characterization of plasmacytoid dendritic cells from Flt3 ligand and granulocytemacrophage colony-stimulating factor-treated mice. Blood 2001;98:3520-3526.

9 Nakano H, Yanagita M, Gunn MD. CD11c(+)B220(+) Gr-1(+) cells in mouse lymph nodes and spleen display characteristics of plasmacytoid dendritic cells. J Exp Med 2001;194:1171-1178.
10 Muller-Hermelink HK, Stein H, Steinmann G et al. Malignant lymphoma of plasmacytoid T-cells. Morphologic and immunologic studies characterizing a special type of T-cell. Am J Surg Pathol 1983;7: 849-862.

11 Facchetti F, Jones DM, Petrella T. Blastic plasmacytoid dendritic cells neoplasm. In: Swerdlow SH, Campo E, Harris NL (eds). WHO Classification of Tumours of Haematopoietic and Lymphoid Tissues (ed. 4th), 4th (edn). International Agency for Research on Cancer: Lyon, France, 2008, pp 145-147.

12 Colonna M, Trinchieri G, Liu YJ. Plasmacytoid dendritic cells in immunity. Nat Immunol 2004;5: 1219-1226.

13 Facchetti F, Vermi W, Mason D et al. The plasmacytoid monocyte/interferon producing cells. Virchows Arch 2003;443:703-717.

14 Facchetti F, de Wolf-Peeters C, Mason DY et al. Plasmacytoid T cells. Immunohistochemical evidence for their monocyte/macrophage origin. Am J Pathol 1988;133:15-21.

15 Liu YJ. IPC: professional type 1 interferon-producing cells and plasmacytoid dendritic cell precursors. Annu Rev Immunol 2005;23:275-306.

16 Swiecki M, Colonna M. Type I interferons: diversity of sources, production pathways and effects on immune responses. Curr Opin Virol 2011;1:463-475.

17 Swiecki M, Colonna M. Unraveling the functions of plasmacytoid dendritic cells during viral infections, autoimmunity, and tolerance. Immunol Rev 2010;234: 142-162.

18 Reynolds G, Haniffa M. Human and mouse mononuclear phagocyte networks: a tale of two species? Front Immunol 2015;6:330.

19 Cella M, Facchetti F, Lanzavecchia A et al. Plasmacytoid dendritic cells activated by influenza virus and CD40L drive a potent Th1 polarization. Nat Immunol 2000;1:305-310.

20 Soumelis V, Liu YJ. From plasmacytoid to dendritic cell: morphological and functional switches during plasmacytoid pre-dendritic cell differentiation. Eur J Immunol 2006;36:2286-2292.

21 Bjorck P, Leong HX, Engleman EG. Plasmacytoid dendritic cell dichotomy: identification of IFN-alpha producing cells as a phenotypically and functionally distinct subset. J Immunol 2011;186:1477-1485.

22 Takagi H, Fukaya T, Eizumi K et al. Plasmacytoid dendritic cells are crucial for the initiation of inflammation and $\mathrm{T}$ cell immunity in vivo. Immunity 2011;35:958-971.

23 Reizis B, Bunin A, Ghosh HS et al. Plasmacytoid dendritic cells: recent progress and open questions. Annu Rev Immunol 2011;29:163-183.

24 Charles J, Chaperot L, Salameire D et al. Plasmacytoid dendritic cells and dermatological disorders: focus on their role in autoimmunity and cancer. Eur J Dermatol 2010;20:16-23.

25 Maraskovsky E, Daro E, Roux E et al. In vivo generation of human dendritic cell subsets by Flt3 ligand. Blood 2000;96:878-884.

26 Karsunky H, Merad M, Cozzio A et al. Flt3 ligand regulates dendritic cell development from Flt3+ lymphoid and myeloid-committed progenitors to Flt3+ dendritic cells in vivo. J Exp Med 2003;198: 305-313.

27 Cisse B, Caton ML, Lehner $\mathrm{M}$ et al. Transcription factor E2-2 is an essential and specific regulator of 
plasmacytoid dendritic cell development. Cell 2008;135:37-48.

28 Lee J, Breton G, Oliveira TY et al. Restricted dendritic cell and monocyte progenitors in human cord blood and bone marrow. J Exp Med 2015;212:385-399.

29 Swiecki M, Gilfillan S, Vermi W et al. Plasmacytoid dendritic cell ablation impacts early interferon responses and antiviral NK and CD8(+) T cell accrual. Immunity 2010;33:955-966.

30 Rowland SL, Riggs JM, Gilfillan S et al. Early, transient depletion of plasmacytoid dendritic cells ameliorates autoimmunity in a lupus model. J Exp Med 2014;211:1977-1991.

31 Jing Y, Shaheen E, Drake RR et al. Aging is associated with a numerical and functional decline in plasmacytoid dendritic cells, whereas myeloid dendritic cells are relatively unaltered in human peripheral blood. Hum Immunol 2009;70:777-784.

32 Dzionek A, Fuchs A, Schmidt P et al. BDCA-2, BDCA-3, and BDCA-4: three markers for distinct subsets of dendritic cells in human peripheral blood. J Immunol 2000;165:6037-6046.

33 Dzionek A, Sohma J, Nagafune M et al. BDCA-2, a novel plasmacytoid dendritic cell cell-specific type II C-type lectin, mediates antigen-capture and is a potent inhibitor of interferon-alpha/beta induction. J Exp Med 2001;194:1823-1834.

34 Petrella T, Comeau MR, Maynadie M et al. 'Agranular CD4+ CD56+ hematodermic neoplasm' (blastic NK-cell lymphoma) originates from a population of CD56+ precursor cells related to plasmacytoid monocytes. Am J Surg Pathol 2002;26:852-862.

35 Facchetti F, De Wolf-Peeters C, van den Oord JJ et al. Plasmacytoid $\mathrm{T}$ cells: a cell population normally present in the reactive lymph node. An immunohistochemical and electronmicroscopic study. Hum Pathol 1988;19:1085-1092.

36 Jegalian AG, Facchetti F, Jaffe ES. Plasmacytoid dendritic cells: physiologic roles and pathologic states. Adv Anat Pathol 2009;16:392-404.

37 Müller-Hermelink HK, Kaiserling E, Lennert K. Pseudofollikuläre Nester von Plasmazellen (eines besonderen Typs?)in der paracorticalen Pulpa menschlicher Lymphknoten. Virchows Arch (Cell Pathol) 1973;14:47-56.

38 Boiocchi L, Lonardi S, Vermi W et al. BDCA-2 (CD303): a highly specific marker for normal and neoplastic plasmacytoid dendritic cells. Blood 2013;122:296-297.

39 Herling M, Teitell MA, Shen RR et al. TCL1 expression in plasmacytoid dendritic cells (DC2s) and the related CD4+ CD56+ blastic tumors of skin. Blood 2003;101:5007-5009.

40 Facchetti F, Vermi W, Santoro A et al. Neoplasms derived from plasmacytoid monocytes/interferonproducing cells: variability of CD56 and granzyme B expression. Am J Surg Pathol 2003;27:1489-1492.

41 Marafioti T, Paterson JC, Ballabio E et al. Novel markers of normal and neoplastic human plasmacytoid dendritic cells. Blood 2008;111:3778-3792.

42 Jacob MC, Chaperot L, Mossuz P et al. CD4+ CD56+ lineage negative malignancies: a new entity developed from malignant early plasmacytoid dendritic cells. Haematologica 2003;88:941-955.

43 Vermi W, Facchetti F, Rosati S et al. Nodal and extranodal tumor-forming accumulation of plasmacytoid monocytes/interferon-producing cells associated with myeloid disorders. Am J Surg Pathol 2004;28: 585-595.

44 Chen YC, Chou JM, Ketterling RP et al. Histologic and immunohistochemical study of bone marrow monocytic nodules in 21 cases with myelodysplasia. Am J Clin Pathol 2003;120:874-881.

45 Vitte F, Fabiani B, Benet C et al. Specific skin lesions in chronic myelomonocytic leukemia: a spectrum of myelomonocytic and dendritic cell proliferations: a study of 42 cases. Am J Surg Pathol 2012;36: 1302-1316.

46 Benet C, Gomez A, Aguilar C et al. Histologic and immunohistologic characterization of skin localization of myeloid disorders: a study of 173 cases. Am J Clin Pathol 2011;135:278-290.

47 Pileri SA, Ascani S, Cox MC et al. Myeloid sarcoma: clinico-pathologic, phenotypic and cytogenetic analysis of 92 adult patients. Leukemia 2007;21: 340-350.

48 Orazi A, Chiu R, O'Malley DP et al. Chronic myelomonocytic leukemia: The role of bone marrow biopsy immunohistology. Mod Pathol 2006;19: 1536-1545.

49 Dargent JL, Delannoy A, Pieron $\mathrm{P}$ et al. Cutaneous accumulation of plasmacytoid dendritic cells associated with acute myeloid leukemia: a rare condition distinct from blastic plasmacytoid dendritic cell neoplasm. J Cutan Pathol 2011;38:893-898.

50 Harris NL, Demirjian Z. Plasmacytoid T-zone cell proliferation in a patient with chronic myelomonocytic leukemia. Histologic and immunohistologic characterization. Am J Surg Pathol 1991;15:87-95.

51 Dargent JL, Henne S, Pranger D et al. Tumor-forming plasmacytoid dendritic cells associated with myeloid neoplasms. Report of a peculiar case with histopathologic features masquerading as lupus erythematosus. J Cutan Pathol 2015.

52 Brody JP, Allen S, Schulman P et al. Acute agranular CD4-positive natural killer cell leukemia. Comprehensive clinicopathologic studies including virologic and in vitro culture with inducing agents. Cancer 1995;75:2474-2483.

53 DiGiuseppe JA, Louie DC, Williams JE et al. Blastic natural killer cell leukemia/lymphoma: a clinicopathologic study. Am J Surg Pathol 1997;21: 1223-1230.

54 Herling M, Jones D. CD4+/CD56+ hematodermic tumor: the features of an evolving entity and its relationship to dendritic cells. Am J Clin Pathol 2007;127:687-700.

55 Chan JKC, Jaffe ES, Ralfkiaer E. Blastic NK-cell lymphoma. In: Jaffe ES HN, Stein H, Vardiman JW (eds). Tumours of Haematopoietic and Lymphoid Tissues, 3rd edn. International Agency for Research on Cancer: Lyon, France, 2001, pp 214-215.

56 Lucio P, Parreira A, Orfao A. CD123hi dendritic cell lymphoma: an unusual case of non-Hodgkin lymphoma. Ann Intern Med 1999;131:549-550.

57 Chaperot L, Bendriss N, Manches O et al. Identification of a leukemic counterpart of the plasmacytoid dendritic cells. Blood 2001;97:3210-3217.

58 Chaperot L, Perrot I, Jacob MC et al. Leukemic plasmacytoid dendritic cells share phenotypic and functional features with their normal counterparts. Eur J Immunol 2004;34:418-426.

59 Petrella T, Meijer CJ, Dalac S et al. TCL1 and CLA expression in agranular CD4/CD56 hematodermic 
neoplasms (blastic NK-cell lymphomas) and leukemia cutis. Am J Clin Pathol 2004;122:307-313.

60 Urosevic M, Conrad C, Kamarashev J et al. CD4+CD56+ hematodermic neoplasms bear a plasmacytoid dendritic cell phenotype. Hum Pathol 2005;36:1020-1024.

61 Gopcsa L, Banyai A, Jakab $\mathrm{K}$ et al. Extensive flow cytometric characterization of plasmacytoid dendritic cell leukemia cells. Eur J Haematol 2005;75:346-351.

62 Reichard KK, Burks EJ, Foucar MK et al. CD4(+) CD56 (+) lineage-negative malignancies are rare tumors of plasmacytoid dendritic cells. Am J Surg Pathol 2005;29:1274-1283.

63 Jaye DL, Geigerman CM, Herling M et al. Expression of the plasmacytoid dendritic cell marker BDCA-2 supports a spectrum of maturation among CD4+ CD56+ hematodermic neoplasms. Mod Pathol 2006;19:1555-1562.

64 Pilichowska ME, Fleming MD, Pinkus JL et al. CD4+/CD56+ hematodermic neoplasm ('blastic natural killer cell lymphoma'): neoplastic cells express the immature dendritic cell marker BDCA-2 and produce interferon. Am J Clin Pathol 2007;128: 445-453.

65 Defays A, David A, de Gassart A et al. BAD-LAMP is a novel biomarker of nonactivated human plasmacytoid dendritic cells. Blood 2011;118:609-617.

66 Dijkman R, van Doorn R, Szuhai K et al. Geneexpression profiling and array-based CGH classify CD4+CD56+ hematodermic neoplasm and cutaneous myelomonocytic leukemia as distinct disease entities. Blood 2007;109:1720-1727.

67 Bendriss-Vermare N, Chaperot L, Peoc'h M et al. In situ leukemic plasmacytoid dendritic cells pattern of chemokine receptors expression and in vitro migratory response. Leukemia 2004;18:1491-1498.

68 Maeda T, Murata K, Fukushima T et al. A novel plasmacytoid dendritic cell line, CAL-1, established from a patient with blastic natural killer cell lymphoma. Int J Hematol 2005;81:148-154.

69 Watanabe N, Narita M, Yamahira A et al. Transformation of dendritic cells from plasmacytoid to myeloid in a leukemic plasmacytoid dendritic cell line (PMDC05). Leuk Res 2010;34:1517-1524.

70 Narita M, Watanabe N, Yamahira A et al. A leukemic plasmacytoid dendritic cell line, PMDC05, with the ability to secrete IFN-alpha by stimulation via Tolllike receptors and present antigens to naive $\mathrm{T}$ cells. Leuk Res 2009;33:1224-1232.

71 Petrella T, Bagot M, Willemze R et al. Blastic NK-cell lymphomas (agranular CD4+CD56+ hematodermic neoplasms): a review. Am J Clin Pathol 2005;123: 662-675.

72 Suzuki R, Nakamura S, Suzumiya J et al. Blastic natural killer cell lymphoma/leukemia (CD56-positive blastic tumor): prognostication and categorization according to anatomic sites of involvement. Cancer 2005;104:1022-1031.

73 Petrella T, Dalac S, Maynadie M et al. CD4+ CD56+ cutaneous neoplasms: a distinct hematological entity? Am J Surg Pathol 1999;23:137-146.

74 Assaf C, Gellrich S, Whittaker S et al. CD56-positive haematological neoplasms of the skin: a multicentre study of the Cutaneous Lymphoma Project Group of the European Organisation for Research and Treatment of Cancer. J Clin Pathol 2007;60: 981-989.
75 Bekkenk MW, Jansen PM, Meijer CJ et al. CD56+ hematological neoplasms presenting in the skin: a retrospective analysis of 23 new cases and 130 cases from the literature. Ann Oncol 2004;15:1097-1108.

76 Cota C, Vale E, Viana I et al. Cutaneous manifestations of blastic plasmacytoid dendritic cell neoplasmmorphologic and phenotypic variability in a series of 33 patients. Am J Surg Pathol 2010;34:75-87.

77 Julia F, Petrella T, Beylot-Barry $\mathrm{M}$ et al. Blastic plasmacytoid dendritic cell neoplasm: clinical features in 90 patients. Br J Dermatol 2013;169:579-586.

78 Hwang K, Park CJ, Jang S et al. Immunohistochemical analysis of CD123, CD56 and CD4 for the diagnosis of minimal bone marrow involvement by blastic plasmacytoid dendritic cell neoplasm. Histopathology 2013;62:764-770.

79 Feuillard J, Jacob MC, Valensi F et al. Clinical and biologic features of CD4(+)CD56(+) malignancies. Blood 2002;99:1556-1563.

80 Dalle S, Beylot-Barry $\mathrm{M}$, Bagot $\mathrm{M}$ et al. Blastic plasmacytoid dendritic cell neoplasm: is transplantation the treatment of choice? Br J Dermatol 2010;162: 74-79.

81 Tsagarakis NJ, Kentrou NA, Papadimitriou KA et al. Acute lymphoplasmacytoid dendritic cell (DC2) leukemia: results from the Hellenic Dendritic Cell Leukemia Study Group. Leuk Res 2010;34: 438-446.

82 Rauh MJ, Rahman F, Good D et al. Blastic plasmacytoid dendritic cell neoplasm with leukemic presentation, lacking cutaneous involvement: Case series and literature review. Leuk Res 2012;36:81-86.

83 Pagano L, Valentini CG, Pulsoni A et al. Blastic plasmacytoid dendritic cell neoplasm with leukemic presentation: an Italian multicenter study. Haematologica 2013;98:239-246.

84 Heinicke T, Hutten H, Kalinski $\mathrm{T}$ et al. Sustained remission of blastic plasmacytoid dendritic cell neoplasm after unrelated allogeneic stem cell transplantation-a single center experience. Ann Hematol 2015;94:283-287.

85 Khoury JD, Medeiros LJ, Manning JT et al. CD56(+) TdT(+) blastic natural killer cell tumor of the skin: a primitive systemic malignancy related to myelomonocytic leukemia. Cancer 2002;94:2401-2408.

86 Kazakov DV, Mentzel T, Burg G et al. Blastic natural killer-cell lymphoma of the skin associated with myelodysplastic syndrome or myelogenous leukaemia: a coincidence or more? Br J Dermatol 2003;149: 869-876.

87 Julia F, Dalle S, Duru G et al. Blastic plasmacytoid dendritic cell neoplasms: clinico-immunohistochemical correlations in a series of 91 patients. Am J Surg Pathol 2014;38:673-680.

88 Trimoreau F, Donnard M, Turlure P et al. The CD4+ CD56+ CD116- CD123+ CD45RA+ CD45RO- profile is specific of DC2 malignancies. Haematologica 2003;88: ELT10.

89 Massone C, Chott A, Metze D et al. Subcutaneous, blastic natural killer (NK), NK/T-cell, and other cytotoxic lymphomas of the skin: a morphologic, immunophenotypic, and molecular study of 50 patients. Am J Surg Pathol 2004;28:719-735.

90 Jegalian AG, Buxbaum NP, Facchetti F et al. Blastic plasmacytoid dendritic cell neoplasm in children: diagnostic features and clinical implications. Haematologica 2010;95:1873-1879. 
91 Alayed K, Patel KP, Konoplev S et al. TET2 mutations, myelodysplastic features, and a distinct immunoprofile characterize blastic plasmacytoid dendritic cell neoplasm in the bone marrow. Am J Hematol 2013;88:1055-1061.

92 Martin-Martin L, Lopez A, Vidriales B et al. Classification and clinical behavior of blastic plasmacytoid dendritic cell neoplasms according to their maturation-associated immunophenotypic profile. Oncotarget 2015;6:19204-19216.

93 Garnache-Ottou F, Feuillard J, Ferrand C et al. Extended diagnostic criteria for plasmacytoid dendritic cell leukaemia. Br J Haematol 2009;145: 624-636.

94 Leroux D, Mugneret F, Callanan M et al. CD4(+), CD56 (+) DC2 acute leukemia is characterized by recurrent clonal chromosomal changes affecting 6 major targets: a study of 21 cases by the Groupe Francais de Cytogenetique Hematologique. Blood 2002;99: 4154-4159.

95 Wiesner $\mathrm{T}$, Obenauf $\mathrm{AC}$, Cota $\mathrm{C}$ et al. Alterations of the cell-cycle inhibitors p27(KIP1) and p16(INK4a) are frequent in blastic plasmacytoid dendritic cell neoplasms. J Invest Dermatol 2010;130: 1152-1157.

96 Lucioni M, Novara F, Fiandrino G et al. Twenty-one cases of blastic plasmacytoid dendritic cell neoplasm: focus on biallelic locus 9p21.3 deletion. Blood 2011;118:4591-4594.

97 Jardin F, Ruminy P, Parmentier F et al. TET2 and TP53 mutations are frequently observed in blastic plasmacytoid dendritic cell neoplasm. Br J Haematol 2011;153:413-416.

98 Stenzinger A, Endris V, Pfarr N et al. Targeted ultradeep sequencing reveals recurrent and mutually exclusive mutations of cancer genes in blastic plasmacytoid dendritic cell neoplasm. Oncotarget 2014;5:6404-6413.

99 Menezes J, Acquadro F, Wiseman $\mathrm{M}$ et al. Exome sequencing reveals novel and recurrent mutations with clinical impact in blastic plasmacytoid dendritic cell neoplasm. Leukemia 2014;28:823-829.

100 Sapienza MR, Fuligni F, Agostinelli C et al. Molecular profiling of blastic plasmacytoid dendritic cell neoplasm reveals a unique pattern and suggests selective sensitivity to NF-kB pathway inhibition. Leukemia 2014;28:1606-1616.

101 Reimer P, Rudiger T, Kraemer D et al. What is CD4+CD56+ malignancy and how should it be treated? Bone Marrow Transplant 2003;32:637-646.

102 Roos-Weil D, Dietrich S, Boumendil A et al. Stem cell transplantation can provide durable disease control in blastic plasmacytoid dendritic cell neoplasm: a retrospective study from the European Group for Blood and Marrow Transplantation. Blood 2013;121: 440-446.

103 Dietrich S, Andrulis M, Hegenbart U et al. Blastic plasmacytoid dendritic cell neoplasia (BPDC) in elderly patients: results of a treatment algorithm employing allogeneic stem cell transplantation with moderately reduced conditioning intensity. Biol Blood Marrow Transplant 2011;17: 1250-1254.

104 Aoki T, Suzuki R, Kuwatsuka Y et al. Long-term survival following autologous and allogeneic stem cell transplantation for blastic plasmacytoid dendritic cell neoplasm. Blood 2015;125:3559-3562.

105 Frankel AE, Woo JH, Ahn C et al. Activity of SL-401, a targeted therapy directed to interleukin-3 receptor, in blastic plasmacytoid dendritic cell neoplasm patients. Blood 2014;124:385-392.

106 Angelot-Delettre F, Roggy A, Frankel AE et al. In vivo and in vitro sensitivity of blastic plasmacytoid dendritic cell neoplasm to SL-401, an interleukin-3 receptor targeted biologic agent. Haematologica 2015;100:223-230.

107 Laribi K, Denizon N, Ghnaya H et al. Blastic plasmacytoid dendritic cell neoplasm: the first report of two cases treated by 5-azacytidine. Eur J Haematol 2014;93:81-85. 